\title{
A biological survey method applied to seafloor massive sulphides (SMS) with contagiously distributed hydrothermal-vent fauna
}

\author{
P. C. Collins ${ }^{1, *}{ }^{,}$R. Kennedy ${ }^{1}$, C. L. Van Dover ${ }^{2}$ \\ ${ }^{1}$ Zoology Department, School of Natural Sciences, National University of Ireland Galway, Ireland \\ ${ }^{2}$ Division of Marine Science and Conservation, Nicholas School of the Environment, Duke University, \\ Beaufort North Carolina 28516, USA
}

\begin{abstract}
Strategies for mitigation of seafloor massive sulphide (SMS) extraction in the deep sea include establishment of suitable reference sites that allow for studies of natural environmental variability and that can serve as sources of larvae for re-colonisation of extracted hydrothermal fields. In this study, we characterize deep-sea vent communities in Manus Basin (Bismarck Sea, Papua New Guinea) and use macrofaunal data sets from a proposed reference site (South Su) and a proposed mine site (Solwara 1) to test the hypothesis that there was no difference in macrofaunal community structure between the sites. We used dispersion weighting to adjust taxa-abundance matrices to down-weight the contribution of contagious distributions of numerically abundant taxa. Faunal assemblages of 3 habitat types defined by biogenic taxa (2 provannid snails, Alviniconcha spp. and Ifremeria nautilei; and a sessile barnacle, Eochionelasmus ohtai) were distinct from one another and from the vent peripheral assemblage, but were not differentiable from mound-to-mound within a site or between sites. Mussel and tubeworm populations at South $\mathrm{Su}$ but not at Solwara 1 enhance the taxonomic and habitat diversity of the proposed reference site.
\end{abstract}

KEY WORDS: Deep-sea mining $\cdot$ Dispersion weighting $\cdot$ Manus Basin $\cdot$ Marine reserves $\cdot$ Solwara 1

\section{INTRODUCTION}

Seafloor massive sulphides (SMS) form chimneylike deposits by precipitation of metal sulphides as acidic hydrothermal fluids exit the seafloor along the margins of tectonic plates (ocean ridge systems, volcanic arcs, or spreading centers of back-arc basins; Humphris et al. 1995). These chimneys may have decadal lifespans (Embley et al. 1998, Soule et al. 2007, Marcus et al. 2009,) and, where hydrothermal activity persists, SMS mounds build by collapse and coalescence of chimneys (Humphris et al. 1995), accumulating over thousands of years (Solomon \& Walshe 1979). SMS mounds are rich in iron pyrite and some may contain high-grade ores, attracting the interest of deep-water extractive industries. SMS samples from the PACMANUS hydrothermal area in Manus Basin (Papua New Guinea), for example, averaged $27 \mathrm{wt} \%$ zinc and $11 \mathrm{wt} \%$ copper, with $200 \mathrm{~g}$ silver and $30 \mathrm{~g}$ of gold per ton as important by-products of SMS extraction (Herzig et al. 1999).

The International Seabed Authority, which has jurisdiction over mineral resources in areas beyond national jurisdictions, lists 327 hydrothermal vent sites in the world's oceans, and many more vent sites are believed to exist in uncharted waters (Baker \& German 2004). Of the known sites, less than a third have substantial SMS deposits (Hoagland et al. 2010). Commercial interests are currently focused on relatively shallow $(<2000 \mathrm{~m})$ back-arc basin or arc volcano sites of the south-western Pacific, which are within territorial waters (Hoagland et al. 2010). 
In addition to hosting commercial-grade ores, SMS deposits associated with active hydrothermal venting typically support benthic communities dominated by large, biomass-rich populations of invertebrate species in symbiosis with chemoautotrophic bacteria. These invertebrate species are often endemic to vent habitats. Populations of these species together with a diversity of associated organisms will be removed by mineral extraction (Van Dover 2010) unless measures are taken to mitigate impacts. One element of a mitigation strategy is to establish reference areas (no extraction) of equal or greater biodiversity upstream of areas to be disturbed (Van Dover 2007). The reference concept in this instance is predicated in part on the assumption that suitable vent habitat will remain or develop upon cessation of extraction activities, with organisms at the reference site expected to serve as brood stock to seed colonization of new vent habitat in the extracted area.

A design criterion for suitability of a vent field as a reference is that the reference area and the targeted extraction area share similar species and community structure (Green 1979). Measures of community structure require an understanding of how organisms are distributed (Legendre \& Legendre 1999). Most deep-sea hydrothermal-vent ecosystems are dominated by one or more large foundation species such as tubeworms, mussels, clams, or snails that host chemoautotrophic endosymbiotic bacteria (Van Dover 2000). Populations of these animals have a contagious distribution (Douglas 1980), i.e. they are strongly clustered. In quantitative samples, foundation species and their dominant associated taxa are recorded not only in ones and twos, but in tens and hundreds. These taxa have a non-Poisson distribution, with group means and variances differing across samples. This is a problematic condition when multivariate analyses are applied, since the capture of each individual is not an independent event; each capture should not be given equal weighting. The traditional response to contagiously distributed species or communities in shallowwater benthic studies is to square-root-transform the data. This method is usually carried out without identifying the statistical and biological grounds for transformations (Clarke et al. 2006). Such data pre-treatments are crude and take no consideration of the structure of counts of individual taxa. An alternative is to apply a dispersion-weighting index to obviate issues created by contagious distributions and traditional data transformations (Clarke et al. 2006).

One of the primary concerns when carrying out biological surveys is the creation of data sets that meet assumptions necessary for robust analyses
(Warwick \& Clarke 1996), and good experimental design is necessary in the planning stage of impact surveys (Underwood 1991, 1992, 1994). Here we use a fully balanced, nested experimental design and dispersion weighting (Clarke et al. 2006) on a macrofaunal data set sampled from contagiously distributed invertebrate communities at a proposed mine site (Solwara 1) and a proposed reference site (South $\mathrm{Su}$ ) in the Manus Basin to establish baseline data sets prior to any extractive activity. We test the hypothesis that the proposed mine and reference areas share the same community structure. We characterize the invertebrate communities (species composition, faunal assemblages, diversity, etc.) and we assess the quality of a proposed mitigation strategy based on a reference concept in a setting where community structure was poorly known.

\section{METHODS}

The study area lies in Manus Basin, a fast-spreading back-arc basin (>100 $\mathrm{mm} \mathrm{yr}^{-1}$; Both et al. 1986) in the eastern part of the Bismarck Sea (Fig. 1A). Previous studies of community structure at hydrothermal vents in this area were primarily descriptive (Galkin 1997, Hashimoto et al. 1999, Desbruyères et al. 2006, Erickson et al. 2009). Two SMS deposits were used for this comparative study (Fig. 1B): Solwara 1 $\left(1553 \mathrm{~m}\right.$ depth; $\left.3.788^{\circ} \mathrm{S}, 152.093^{\circ} \mathrm{E}\right)$, a site proposed for commercial extraction activities, and South $\mathrm{Su}$ $\left(1399 \mathrm{~m} ; 3.811^{\circ} \mathrm{S}, 152.104^{\circ} \mathrm{E}\right)$, proposed as a reference site. Solwara 1 and South Su are separated by an active subsea volcano, North $\mathrm{Su}$, which also supports chemosynthetic habitats. Solwara 1 is a mound rising $200 \mathrm{~m}$ from the seafloor to the northwest of North Su with rich SMS deposits extending, on average, more than $10 \mathrm{~m}$ into the sediment in 5 proposed mining locations. Solwara 1 was selected as a principal extraction target because of its high-grade ores. South Su was chosen as a reference site because of its proximity (within $2.5 \mathrm{~km}$ ) to Solwara 1 and its apparent similarity in biology and topography, differing by less than $200 \mathrm{~m}$ in depth. Our study was designed to test the hypothesis that there was no significant difference in macrofaunal community structure between Solwara 1 and South Su.

\section{Effects of mining and mitigation}

The proposed mineral extraction will remove an area of approximately $0.112 \mathrm{~km}^{2}$ of vent habitat 

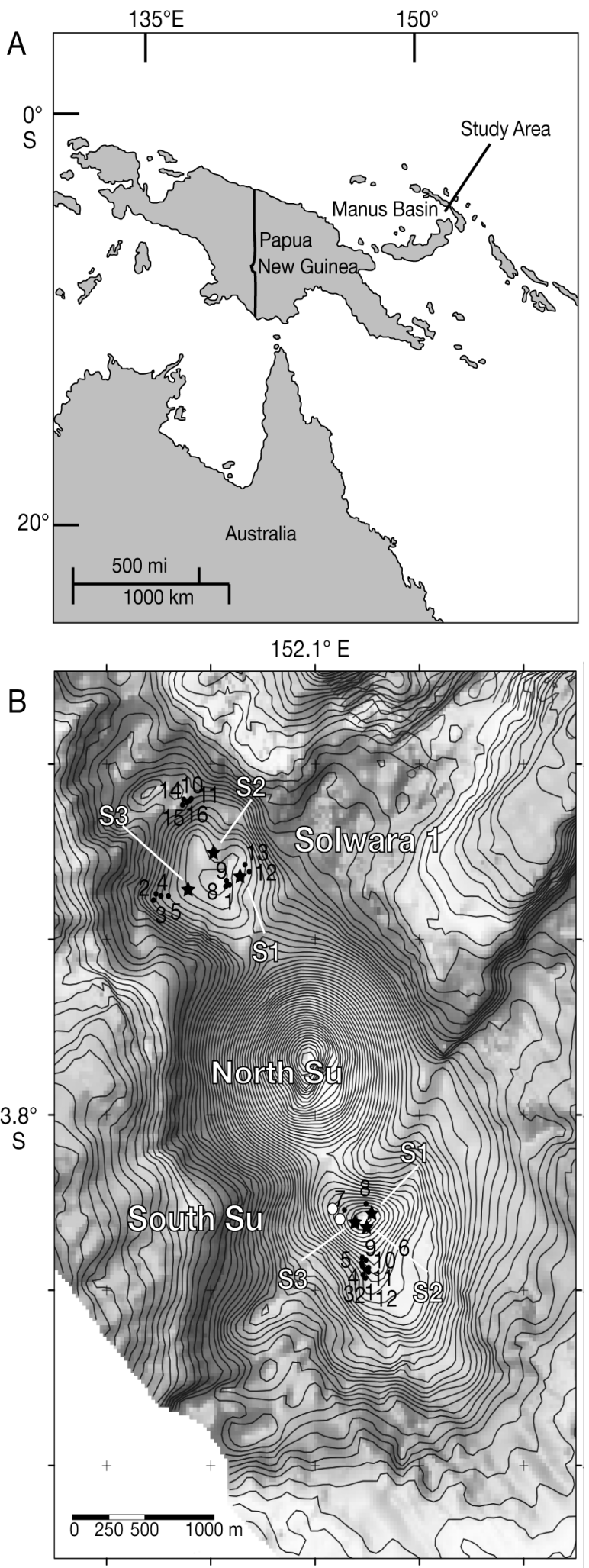

Fig. 1. (A) Location of the study area within the Manus Basin, Papua New Guinea. (B) Locations of Solwara 1 and South Su sites. $(\star)$ Active vent mounds. $(\bullet)$ Vent peripheral samples. (O) Tubeworm assemblages. A large, active volcano, North $\mathrm{Su}$, separates Solwara 1 from South $\mathrm{Su}$
(Gwyther 2008) at the Solwara 1 site. Possible effects and mitigation strategies have been outlined in Gwyther (2008) and Van Dover (2010). The potential impact that this study focuses on is the removal of the local faunal community from the mined area. The proposed mitigation for this is to use a reference plot that will allow for re-population of the faunal communities following the cessation of mining activities. Other potential impacts are discussed briefly below, summarising the environmental impact statement for the project (Gwyther 2008) and its appendices.

The potentially impacted area extends beyond the extraction area because of sediment plumes. Prior to mining, unconsolidated surface sediment will be stripped from the bottom. In total, approximately $130000 \mathrm{t}$ of unconsolidated sediment and $115000 \mathrm{t}$ of competent waste rock, which is below the mine cut-off grade, will be side cast to dedicated disposal sites in the mine area during mining operations. This will create plumes of sediment near the seafloor that may affect water quality. There will be physical disturbance due to burial and sedimentation. Sediment and competent waste material are likely to remain near the seafloor and not be exposed to any increases in temperature or oxidation. They are unlikely to undergo geochemical changes. Hydrodynamic modelling predicts that the coarser fraction of disposed material will settle immediately downslope of the disposal points and form mounds $500 \mathrm{~mm}$ deep. Lighter materials will travel further from the disposal points. Fine material will form plumes near the seafloor. The plumes will settle on the seafloor no further than $1 \mathrm{~km}$ from the discharge points. The resultant footprint depth will be between 0.18 and $500 \mathrm{~mm}$ and cover an area just over $2.3 \mathrm{~km}^{2}$. Any deposition that occurs further afield will be at a rate less than natural sedimentation rates.

The process of mining will involve the use of a Seafloor Mining Tool (SMT) that incorporates tools for cutting up the vent chimneys and hydrothermal deposits and suctioning the material to a Mining Support Vessel (MSV) at the surface. Very little fine material will be lost at this stage. The ore will be dewatered on the MSV and transferred to a barge for transport to shore for processing. The return water will contain only particles $<8 \mu \mathrm{m}$ and be discharged upwards into the water column at a height of 25 to $50 \mathrm{~m}$ above the seabed to minimise the extent of the plume created. The plumes from the SMT and the return water will be discharged in the bathypelagic layer below the depth of the naturally occurring plume from North Su. Plume dispersion modelling predicts that the plume from the return water will flocculate and settle 5 to $10 \mathrm{~km}$ to the west and north- 
west of Solwara 1. Predicted maximum deposition is less than $0.1 \mathrm{~mm}$. This sedimentation rate is less than the natural rate measured at Solwara 1 and South Su. Sediment in the return water may become geochemically activated by being exposed to increased temperatures and oxidation at the surface. The plume from the SMT is predicted to be negligible during mining.

The sediment plumes and crushed competent material were determined to be toxic in laboratory studies using an intertidal amphipod because of elevated heavy metal levels (median lethal concentration for Melita plumulosa in a $10 \mathrm{~d}$ whole sediment test was $4.3 \%$ ). Ore concentrations of less than $1 \%$ had no significant effect on survival of $M$. plumulosa. Predicting where the deposition of a plume will be equivalent to a 100-fold dilution in the bulk sediment is difficult. Sedimentation from the naturally occurring vent plumes is likely to select for macrofauna that are tolerant to elevated heavy metals in the area adjacent to the vent field. It is possible that the deposition of sediment plumes from return water on areas remote from hydrothermal activity will cause deleterious effects to animals not normally exposed to mineralised sediments. The planned mitigation measure is to discharge the return water below the plume from South $\mathrm{Su}$ and North $\mathrm{Su}$, in which case the return water plume may be undetectable at distance from Solwara 1 when combined with the natural plume. Dispersion modelling indicates the $95 \%$ protection level of the ANZECC/ARMCANZ (2000) water quality guidelines for suspended sediments will be reached at no more than $900 \mathrm{~m}$ from the point of discharge because the required 5000-fold dilution factor will be reached more than $50 \%$ of the time at that distance. This plume is very unlikely to affect South $\mathrm{Su}$ because of the distance between the sites and the direction of the bottom currents.

Water column profiles $(\mathrm{n}=115)$ with a conductivity temperature depth (CTD) probe over the period 1985 to 2008 demonstrated that the water column in the study area is consistently stratified (CSIRO 2005, 2007, Gwyther 2008). Currents in the upper $400 \mathrm{~m}$ are strongly influenced by the semi-diurnal tides and seasonality associated with monsoons and the Southern Ocean oscillation. Current meter deployments have shown that net water movement at Solwara 1 between 800 and $1200 \mathrm{~m}$ water depth is generally to the east-northeast but can move to the west on occasions. Naturally occurring particulate plumes in the area were measured between 1996 and 1997 using sediment traps (Hrischeva \& Scott 2008). These plumes largely originate from North $\mathrm{Su}$ but contain material from South Su and Solwara 1 also. The foot- print affected by the plumes is determined by the currents at 800 to $1200 \mathrm{~m}$, causing Solwara 1 to have a higher sedimentation rate $\left(0.95 \mathrm{~g} \mathrm{~m}^{-2} \mathrm{~d}^{-1}\right)$ than South $\mathrm{Su}\left(0.82 \mathrm{~g} \mathrm{~m}^{-2} \mathrm{~d}^{-1}\right)$. Both areas have sedimentation rates that are much higher than typical rates in the deep sea at these latitudes of between 0.005 and $0.055 \mathrm{~g} \mathrm{~m}^{-2} \mathrm{~d}^{-1}$ (Lampitt \& Antia 1997).

Currents at and immediately above Solwara 1 are weak, averaging $6 \mathrm{~cm} \mathrm{~s}^{-1}$, and are dominated by tidal influences on the short, daily, time scale (Wright 2008). On time scales relevant to larval metamorphoses, weeks to months, net current flow is from the southeast to the northwest, away from North $\mathrm{Su}$ and South $\mathrm{Su}$ and towards Solwara 1. Larvae entrained in hydrothermal plumes coming off South Su should be transported towards Solwara 1. Mixing with the plume from North $\mathrm{Su}$ and the daily action of the tide should act to homogenise the supply of larvae across the study area.

The sediments of the area are volcanic silty sands that mainly originate from frequent violent volcanic eruptions at North Su (Binns 2004). The sediment is largely unconsolidated and depths range between 0.25 and $6.0 \mathrm{~m}$. Local anomalies in sediment composition such as elevated levels of arsenic and trace metals from nearby hydrothermal plumes or chimney fragmentation are short-lived (Gwyther 2008). The sediments have elevated levels of copper that may make them inhospitable for macroinfauna. Macrofaunal diversity and abundance in sediment communities at both South Su and Solwara 1 was low compared to other vent sites (Levin et al. 2008, 2009). Macrofauna retained on a $300 \mu \mathrm{m}$ sieve was examined. The communities were dominated by Tanaid crustacea, polychaetes of the genus Minuspio and bivalves of the superfamily Nuculanoida. The infaunal distribution was very variable, possibly reflecting high levels of ambient stress in the area. There were significant differences between active and inactive samples and between Solwara 1 and South Su. The taxonomic composition of the infauna is similar to that found at other vent sites (Levin et al. 2008, 2009). Where abundances were elevated, the community was usually numerically dominated by the opportunistic polychaete Minuspio spp.

Study sites were sampled in March and April 2007 (Luk Luk cruise) from the CS 'Wave Mercury', using a Perry Slingsby TS200 remotely operated vehicle (ROV) modified for biological sampling with bioboxes and a 4-chambered slurp gun. Three sets of samples were collected: quantitative samples from active hydrothermal vents, semi-quantitative samples from peripheral inactive sites, and qualitative samples from throughout the study area. Due to the dynamic 
nature of the vent environment, the sampling design provided a snapshot of the ecosystem and did not include a temporal component. Active vents were defined as sulphide chimneys with obvious venting of warm to hot fluids and visually dominated by vent endemic taxa (e.g. Alviniconcha spp., Ifremeria nautilei, Eochionelasmus ohtai). Vent peripheral samples were collected from sulphide or basalt outcrops defined by the absence of vent endemic taxa hosting chemoautotrophic endosymbionts and without visual evidence of warm-water or black-smoker effluents.

A $2 \times 3 \times 3 \times 3$ nested sampling strategy was employed for active hydrothermal vents: 2 sites (Solwara 1 and South Su), 3 mounds per site, 3 assemblages per mound, and 3 replicate samples per assemblage, resulting in 27 faunal samples at each site. Mounds were selected for sampling on the visual criterion of having sufficient biomass to permit responsible sampling (Devey et al. 2007). The 3 assemblages sampled were selected based on visual observations made by Erickson (2007) of apparent faunal groupings. They correspond to 2 co-occurring cryptic species of Alviniconcha spp. (a large provannid snail with a light-colored, hairy periostracum); Ifremeria nautilei (a large provannid snail with a black-brown, smooth periostracum); and Eochionelasmus ohtai (a sessile barnacle). These assemblages are herein referred to as Alviniconcha, Ifremeria, and Eochionelasmus. Both snails host endosymbiotic bacteria in their gills on which they rely for most of their nutrition (Suzuki et al. 2006a,b) and form patches of stacked individals (Fig. 2A-C). E. ohtai is a primitive, suspension-feeding sessile barnacle that forms encrustations on sulfide chimneys (Fig. 2D)

For Alviniconcha and Ifremeria assemblages, discrete quantitative samples of $0.25 \mathrm{~m}^{2}$, measured using onboard laser sights were initially lightly suctioned with the ROV slurp gun into a sealed chamber. Each replicate sample had a dedicated slurp chamber. A $30 \mathrm{~cm}$ long scoop made from $20 \mathrm{~cm}$ diameter PVC pipe was used to collect larger snails and associated fauna from the $0.25 \mathrm{~m}^{2}$ sample; full scoops were placed within a closable 'bio-box'. To complete the sampling effort, the $0.25 \mathrm{~m}^{2}$ sample zone was vigorously re-suctioned into the same chamber used for the initial suctioning; this was to collect any tubicolous or tightly attached specimens living below the layer of snails. ROV operators were careful to sample each $0.25 \mathrm{~m}^{2}$ sample exhaustively and we determined that as the majority of the taxa were sessile or slow moving our samples are quantitative. On deck, samples were immediately chilled and either processed immediately or stored at $4^{\circ} \mathrm{C}$ for $<2 \mathrm{~h}$. For Eochionelasmus, sections of sulphide chimneys $\left(\geq 0.25 \mathrm{~m}^{2}\right)$ with barnacle coverage were initially vigorously suction-sampled into a dedicated slurp chamber, one per replicate, before being broken off and placed in dedicated chimney bins, a separate bin per replicate, for transfer to the surface on a riser. Rigorous suctioning of the sampled area removed any loose organisms; however the bins were also searched for fauna that may have dropped off upon recovery. In the ship's wet lab all the epibiota within the $0.25 \mathrm{~m}^{2}$ sample area, delineated by a quadrat, were picked off the chimney segment, added to the taxa collected from the slurp chambers, and processed. As this was a hydrothermal vent ecosystem, with the visually dominant taxa comparable in size to shallow water taxa, only macrofauna retained on a $0.5 \mathrm{~mm}$ aperture sieve were retained for further study.

Peripheral sites selected for study were colonized by macrofauna, including bamboo coral (Keratoisis sp.; Fig. 2E,F), hydrozoan mats (Fig. 2G), carnivorous sponges (Abyssocladia sp.; Fig. 2G), and stalked barnacles, (Fig. 2H) that allowed for representative sampling without obliteration of the entire assemblage. The majority of the vent peripheral taxa were not visible by video, being hidden in hydrozoan mats or too small, thus necessitating the physical removal of samples. Suitable samples (discrete inactive habitats located at least $10 \mathrm{~m}$ from an active vent site, Fig. 1) were more scarce at South $\mathrm{Su}(\mathrm{n}=12$ sites sampled) than at Solwara 1 ( $\mathrm{n}=15$ sites sampled). Emphasis was placed on retrieval of at least 5 representative specimens of the biomass-dominant taxa from $0.25 \mathrm{~m}^{2}$ quadrats using a slurp/scrape/slurp method or by recovering pieces of the substratum. The nature of the study does not allow for the assessment of the potential downstream impacts of any future mining in adjacent areas; rather the study focuses on community differences between sites.

Qualitative samples were collected using various sampling methods. These were samples of opportunity that focused on capturing maximum diversity at each site, including mussels, tubeworms, and their associated fauna (see Fig. 5). Mobile and large taxa were photo-documented on an ad hoc basis.

\section{Sample processing}

Sample material was immediately fixed in $10 \%$ borax-buffered formalin for a minimum of $24 \mathrm{~h}$ and preserved in $70 \%$ ethanol in labelled plastic containers. On shore, preserved samples were rinsed with fresh water and sorted under light in white plastic trays. Taxa were identified to the lowest taxon 

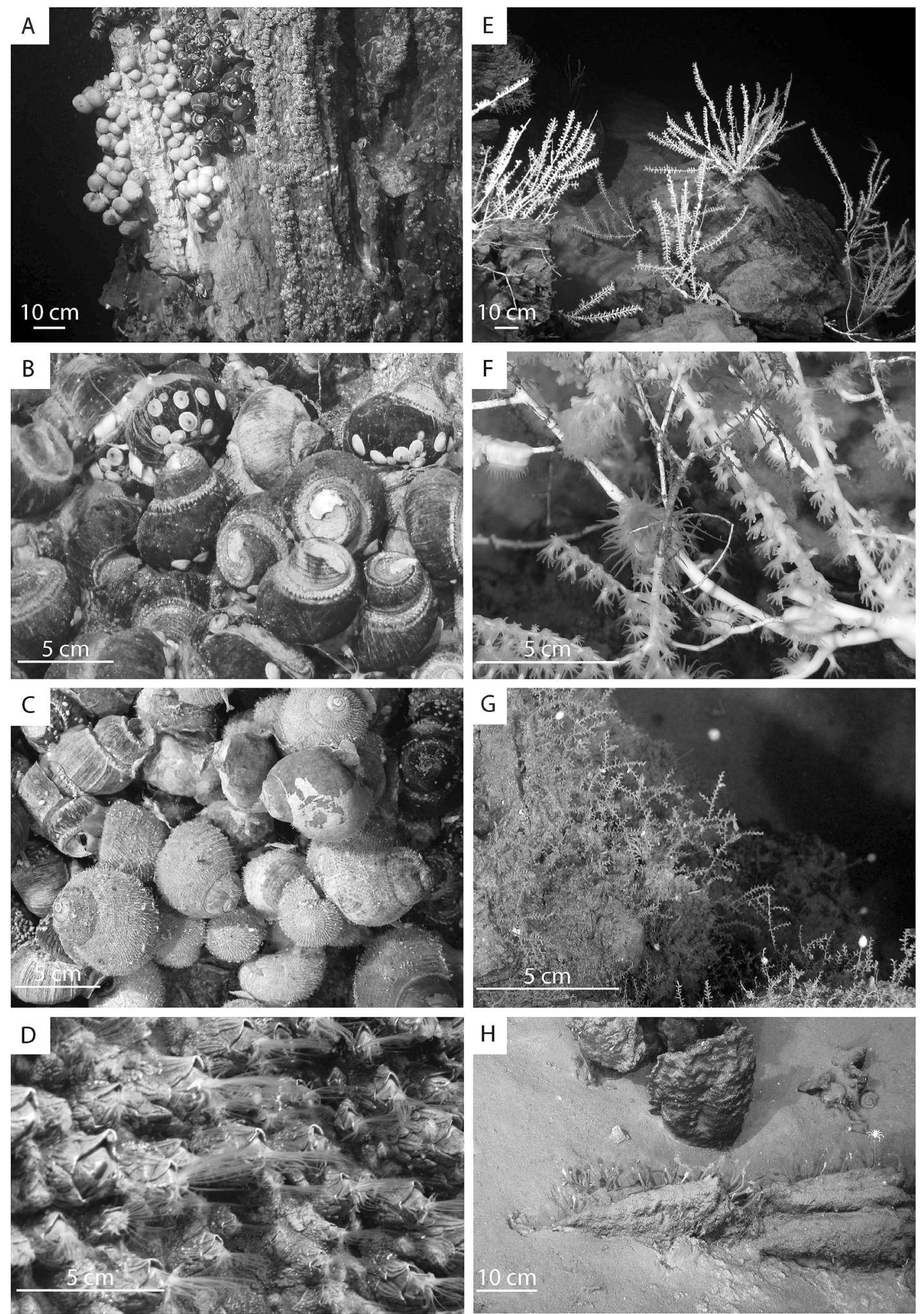

Fig. 2. (A-D) Characteristic active vent and (E-H) peripheral vent fauna from Manus Basin. (A) Ifremeria, Alviniconcha, and Eochionelasmus patches on a sulfide chimney. The pale snails in the centre left are Alviniconcha spp. The darker snails to the upper right of the Alviniconcha spp. are Ifremeria nauteli. The sessile barnacle Eochionelasmus ohtaii is seen to the right of the I. nautilei in the centre and right of the photograph. (B) Ifremeria nautilei with associated Olgasolaris tollmani (limpets). (C) Alviniconcha spp. (D) Eochionelasmus ohtaii. (E) A dense patch of Keratoisis sp. (F) Keratoisis sp. with associated anemone. (G) Hydroids and Abyssocladia sponges. (H) Vulcanolepas sp. Images courtesy of Nautilus Minerals 
possible and enumerated. Initial identifications were made using Desbruyères et al. (2006) followed by review of original descriptions and consultation with taxonomic experts (Table $\mathrm{S} 1$ in the supplement at www.int-res.com/articles/suppl/m452p089_supp .pdf). A voucher collection is maintained at the Duke University Marine Laboratory.

\section{Dispersion weighting}

Foundation taxa were contagiously distributed, i.e. clumped, a common effect throughout epifuanal communities. To compensate, dispersion weighting was applied to minimize the effects of contagiously distributed taxa. The increased diversity associated with increased abundance of the foundation species is the 'response' in this analysis. Species abundances for quantitative samples were dispersion weighted using assemblage as the factor in PRIMER v6 (Clarke \& Gorley 2006). An observed index of dispersion $(D)$ for each group was calculated as the ratio of the sample variance to the sample mean for each replicate. Downweighting was achieved by dividing the replicate counts of each taxon by the average index of dispersion. Taxa that were strongly clustered were downweighted heavily $(D>>1)$, while randomly distributed taxon abundances $(D \approx 1)$ remained unchanged after dispersion weighting (Valesini et al. 2004).

\section{Sampling sufficiency}

The sufficiency of the sampling effort was investigated by calculating the ratio of standard error of the mean to arithmetic mean for total number of individuals, number of taxa and Shannon-Wiener diversity index (Shannon \& Weaver 1949). Elliott (1977) suggested that a standard error equal to $20 \%$ of the mean is considered a reasonable error in benthic studies. Total number of taxa, total number of individuals and Shannon diversity index $\left.\left(H_{\text {loge }}\right)\right]$ were calculated on raw assemblage data sets with the subroutine Diverse PRIMER v6 (Clarke \& Gorley 2006, Clarke et al. 2006).

\section{Multivariate analyses of active vent faunal samples}

Multivariate analyses for quantitative samples were carried out using PRIMER v6 (Clarke \& Gorley 2006), with further analyses using the add-on package PERMANOVA+ (Anderson et al. 2008). Bray-Curtis similarity matrices were constructed with dispersion- weighted faunal abundances for each sample (Clarke $\&$ Warwick 2001, Clarke et al. 2006). A principal coordinates ordination (PCO) was carried out on the similarity matrix to investigate the relative distribution of samples and the amount of variance explained by the model. To highlight significant differences among groups, a 3-way nested permutational multivariate analysis of variance (PERMANOVA) was carried out on the similarity matrix, with Assemblage nested in Mound, and Mound nested in Site. P-values were determined both by permutation and by comparison to asymptotes estimated by Monte Carlo simulation (Anderson et al. 2008). To determine contributions of different taxa to similarity within groups and dissimilarity between groups, a 1-way similarity percentages (SIMPER) analysis (Clarke 1993) was carried out on the dispersion-weighted taxa-by-station matrix using Site or Assemblage as the factor. The SIMPER routine in PRIMER v6 investigates the role of individual taxa in contributing to the separation between groups of samples by decomposing the average Bray-Curtis dissimilarities between all pairs of samples, one from each group, into percentage contributions from each taxon. The closeness of samples within a group is similarly determined by decomposing all similarities among samples within a group into percentage contributions from each taxon. Taxa are listed in decreasing order of contribution (Clarke \& Gorley 2006).

\section{Multivariate analyses of vent peripheral samples}

Presence-absence data from semi-quantitative vent peripheral samples were used to calculate a Bray-Curtis similarity matrix using PRIMER v6 (Clarke \& Gorley 2006). To test for significant differences between sites, a 1-way unrestricted PERMANOVA was performed with Site as the factor on the similarity matrix.

\section{Combined active vent and vent periphery multivariate analyses}

Quantitative sample sets for vent peripheral and active vents were merged using presence-absence data only, with vent periphery as a fourth 'assemblage' (i.e. in addition to Alviniconcha, Ifremeria, and Eochionelasmus). A Bray-Curtis matrix was calculated in PRIMER v6 (Clarke \& Gorley 2006) and a PCO was carried out on the similarity matrix to investigate the relative distribution of samples and the amount of variance explained by the model. To test 
for significant differences between sites and assemblages, a 2-way nested PERMANOVA was carried out on the similarity matrix, with assemblage nested in site. P-values were determined both by permutation and by comparison to asymptotes estimated by Monte Carlo simulation (Anderson et al. 2008). Taxa occurring in only active or peripheral samples (i.e. vent 'endemic' or peripheral 'endemic') were identified using a 1-way SIMPER analysis (Clarke \& Gorley 2006) of presence-absence data.

\section{RESULTS}

\section{Overview of community structure, active vents (quantitative samples)}

A total of 49 taxa (24805 ind.) were collected in quantitative samples from Solwara 1 and South $\mathrm{Su}$ assemblages, with 23 of these taxa ( 50\%) shared by both sites (Table S2 in the supplement). Solwara 1 quantitative samples returned 33 taxa (7278 ind.), with 10 taxa in these samples not present at South $\mathrm{Su}$ (Table 1). South Su quantitative samples returned 39 taxa (17 527 ind.), with 16 taxa in these samples not present at Solwara 1 (Table 1). The number of taxa is provisional and is expected to increase as taxonomic experts validate identifications. The difference of more than 10000 individuals in total macroinvertebrate abundance between Solwara 1 and South $\mathrm{Su}$ samples was due to enormous numbers of the limpet Lepetodrilus schrolli in Alviniconcha and Ifremeria samples at South Su.

Solwara 1 samples were numerically dominated by Lepetodrilus schrolli ( $\mathrm{n}=1971$ ind.), Eochionelasmus ohtai ( $\mathrm{n}=1938$ ), and Olgasolaris tollmanni ( $\mathrm{n}=$ 1657 ind.). Most taxa at Solwara 1 (18 or 53\%) were uncommon, i.e. with fewer than 5 individuals in all samples (Table S2 in the Supplement). South Su samples shared the same numerical dominants as Solwara 1: L. schrolli (n=13 189 ind.), E. ohtai (n = 1571 ind.), and O. tollmanni ( $\mathrm{n}=910$ ind.). Sixteen taxa $(44 \%)$ in South Su samples were uncommon. At both sites, the hierarchy of abundance within major taxa was Mollusca (60 to $80 \%$ of ind.) >>> Crustacea (13 to $30 \%$ of ind.) $>$ Annelida (4 to $13 \%$ of ind.).

\section{Overview of community structure, vent periphery (quantitative samples)}

Vent peripheral sites were generally of 2 kinds: bare, vertically oriented deposits dominated by con- spicuous stands or patches of sessile organisms, or horizontally oriented deposits covered with sediment and colonized by infaunal taxa. A total of 91 taxa were recovered from vent peripheral samples (Table 2, Table S3 in the supplement); 32 taxa were common to Solwara 1 and South Su. The number of taxa recovered from Solwara 1 (65 taxa) was greater than that recovered from South Su (58 taxa). Numerical dominants in samples (in decreasing abundance) were: Abyssocladia sp. sponges, an unidentified taxa of amphipod, 2 taxa of stalked barnacles (Vulcanolepas parensis and Poecilasma cf. kaempferi), squat lobsters Munidopsis lauensis, lepetodrilid limpets, and thyasirid clams. Most taxa (>80\%) were represented by fewer than 5 specimens. Eleven taxa generally considered to be endemic to active hydrothermal sites were observed in vent peripheral samples (Table 2).

\section{Test for sampling sufficiency}

The sampling effort was adequate (Table 3). A greater than $20 \%$ ratio of standard error of the mean to arithmetic mean was observed for the total number of individuals in Alviniconcha and vent peripheral assemblages and for the total taxa in vent peripheral samples. The result is expected for vent peripheral samples as they contain a lot of background fauna.

\section{Community similarity, active vents}

Alviniconcha, Ifremeria and Eochionelasmus assemblages are distanced from one another on 2D, unconstrained PCO plots of dispersion-weighted similarity measures, but are not readily differentiated by site (Fig. 3). This result is consistent with characteristic species and abundances associated with each assemblage (Table S2 in the supplement), and the experimental design that ensured that each assemblage would be present on every mound. Average dissimilarity between assemblage pairs was $\geq 88 \%$ (Table 4 ). PERMANOVA results provide further support for significant differences $(p<0.001)$ among assemblages and no significant differences $(p>0.05)$ among mounds (Table 5). Residual variation, which indicates multivariate heterogeneity among samples, was small relative to variation at other scales. The signficance of site depended on whether a permutation or Monte Carlo simulation was used (Table 5). Relative abundances of 7 taxa accounted for more than $70 \%$ of the dissimilarity between Solwara 1 and South $\mathrm{Su}$ (Table 6). Lepetodrilus schrolli was more than 7 times 
Table 1. Taxa-abundance (no. of ind.) distributions by assemblage at Solwara 1 and South Su

\begin{tabular}{|c|c|c|c|c|c|c|c|c|}
\hline & \multirow[b]{2}{*}{$\begin{array}{l}\text { Alvini- } \\
\text { concha }\end{array}$} & \multicolumn{3}{|c|}{ Solwara 1} & \multirow[b]{2}{*}{$\begin{array}{l}\text { Alvini- } \\
\text { concha }\end{array}$} & \multirow{2}{*}{$\begin{array}{c}\text { Sou } \\
\text { Ifremeria }\end{array}$} & \multirow{2}{*}{$\begin{array}{l}\text { Eochione- } \\
\text { lasmus }\end{array}$} & \multirow[b]{2}{*}{ Total N } \\
\hline & & Ifremeria & $\begin{array}{c}\text { Eochione- } \\
\text { lasmus }\end{array}$ & Total N & & & & \\
\hline \multicolumn{9}{|l|}{ Porifera } \\
\hline Abyssocladia sp. & 0 & 1 & 0 & 1 & 0 & 6 & 0 & 6 \\
\hline Cnidaria & 0 & 0 & 0 & 0 & 0 & 0 & 0 & 0 \\
\hline Hydrozoa sp. & 2 & 1 & 0 & 3 & 0 & 0 & 0 & 0 \\
\hline Keratoisis sp. & 0 & 0 & 0 & 0 & 0 & 1 & 0 & 1 \\
\hline \multicolumn{9}{|l|}{ Mollusca } \\
\hline Gastropoda sp. & 0 & 0 & 0 & 0 & 2 & 0 & 0 & 2 \\
\hline Neomphalid n. gen., n. sp. & 0 & 0 & 0 & 0 & 58 & 166 & 0 & 224 \\
\hline Bathyacmaea jonassoni & 0 & 0 & 0 & 0 & 0 & 1 & 0 & 1 \\
\hline Lepetodrilus schrolli & 212 & 1586 & 173 & 1971 & 1043 & 11360 & 786 & 13189 \\
\hline Olgasolaris tollmanni & 105 & 1552 & 0 & 1657 & 52 & 858 & 0 & 910 \\
\hline Shinkailepas spp. & 4 & 1 & 4 & 9 & 16 & 1 & 0 & 17 \\
\hline Puncturella sp. & 0 & 0 & 0 & 0 & 0 & 1 & 0 & 1 \\
\hline Alviniconcha spp. & 184 & 30 & 0 & 214 & 96 & 1 & 0 & 97 \\
\hline Ifremeria sp. & 26 & 230 & 0 & 256 & 14 & 131 & 0 & 145 \\
\hline Provanna n. sp. & 1 & 0 & 0 & 1 & 6 & 0 & 1 & 7 \\
\hline Nuculanoidea n. gen., n. sp. & 0 & 2 & 0 & 2 & 1 & 0 & 0 & 1 \\
\hline Bathymodiolus manusensis & 0 & 0 & 0 & 0 & 2 & 0 & 16 & 18 \\
\hline \multicolumn{9}{|l|}{ Nemertea } \\
\hline Nemertean sp. & 1 & 0 & 0 & 1 & 0 & 0 & 0 & 0 \\
\hline \multicolumn{9}{|l|}{ Annelida } \\
\hline Polychaete sp. 1 & 9 & 0 & 0 & 9 & 0 & 0 & 2 & 2 \\
\hline Polychaete sp. 2 & 0 & 0 & 0 & 0 & 0 & 0 & 2 & 2 \\
\hline Polychaete sp. 3 & 0 & 0 & 0 & 0 & 0 & 0 & 2 & 2 \\
\hline Archinome rosacea & 0 & 0 & 1 & 1 & 0 & 0 & 0 & 0 \\
\hline Hesionidae sp. & 0 & 0 & 0 & 0 & 0 & 1 & 0 & 1 \\
\hline Nereis sp. & 0 & 0 & 35 & 35 & 0 & 0 & 6 & 6 \\
\hline Branchipolynoe sp. & 0 & 0 & 0 & 0 & 0 & 0 & 5 & 5 \\
\hline Branchinotogluma sp. & 0 & 0 & 0 & 0 & 0 & 3 & 1 & 4 \\
\hline Branchinotogluma segonzaci & 1 & 0 & 0 & 1 & 0 & 1 & 0 & 1 \\
\hline Branchinotogluma trifurcus & 6 & 252 & 0 & 258 & 11 & 109 & 2 & 122 \\
\hline Thermopolynoe branchiata & 0 & 0 & 0 & 0 & 0 & 7 & 0 & 7 \\
\hline Spionidae spp. & 1 & 0 & 0 & 1 & 0 & 0 & 0 & 0 \\
\hline Prionspio sp. & 5 & 0 & 0 & 5 & 1 & 2 & 1 & 4 \\
\hline Spiochaetopterus sp. & 3 & 0 & 0 & 3 & 0 & 0 & 0 & 0 \\
\hline Paralvinella juvenile & 2 & 0 & 0 & 2 & 0 & 0 & 0 & 0 \\
\hline Paralvinella sp. & 2 & 0 & 0 & 2 & 0 & 0 & 0 & 0 \\
\hline Paralvinella unidentata & 2 & 0 & 0 & 2 & 8 & 0 & 0 & 8 \\
\hline Paralvinella fijiensis & 17 & 3 & 1 & 21 & 1 & 0 & 0 & 1 \\
\hline Ampharetidae sp. & 0 & 0 & 0 & 0 & 0 & 0 & 4 & 4 \\
\hline Amphisamytha cf. galapagensi & sis 8 & 490 & 97 & 595 & 17 & 327 & 132 & 476 \\
\hline Terebellidae sp. & 0 & 0 & 14 & 14 & 0 & 0 & 1 & 1 \\
\hline \multicolumn{9}{|l|}{ Arthropoda } \\
\hline Ostracod & 0 & 0 & 2 & 2 & 0 & 0 & 0 & 0 \\
\hline Harpactacoid spp. & 30 & 0 & 1 & 31 & 35 & 0 & 2 & 37 \\
\hline Eochionelasmus ohtai & 0 & 2 & 1836 & 1838 & 1 & 25 & 1545 & 1571 \\
\hline Ashinkailepas sp. & 0 & 0 & 0 & 0 & 0 & 0 & 1 & 1 \\
\hline Vulcanolepas parensis & 0 & 0 & 116 & 116 & 0 & 0 & 21 & 21 \\
\hline Chorocaris sp. & 50 & 169 & 0 & 219 & 426 & 173 & 0 & 599 \\
\hline Tanaidacea sp. & 1 & 0 & 0 & 1 & 0 & 0 & 0 & 0 \\
\hline Isopoda sp. & 2 & 0 & 0 & 2 & 0 & 0 & 0 & 0 \\
\hline Amphipoda spp. & 1 & 0 & 0 & 1 & 0 & 2 & 1 & 3 \\
\hline Alvinocaris sp. & 0 & 0 & 0 & 0 & 0 & 4 & 0 & 4 \\
\hline Munidopsis lauensis & 0 & 0 & 0 & 0 & 1 & 0 & 0 & 1 \\
\hline Austinograea alayseae & 2 & 2 & 0 & 4 & 6 & 19 & 0 & 25 \\
\hline Total no. of taxa & 25 & 14 & 11 & 33 & 20 & 22 & 19 & 39 \\
\hline Total no. of individuals & 677 & 4321 & 2280 & 7278 & 1797 & 13199 & 2531 & 17527 \\
\hline
\end{tabular}


Table 2. Number of taxa and abundances in samples from the vent periphery at Solwara 1 and South Su, Manus Basin. indet: undeterminable. ${ }^{*}$ Taxa generally considered to be endemic to active hydrothermal vents

\begin{tabular}{|c|c|c|c|c|c|}
\hline & Solwara 1 & South Su & & Solwara 1 & South $\mathrm{Su}$ \\
\hline Porifera & & & Ophryotrocha sp. & 0 & 1 \\
\hline Abyssocladia sp. & 172 & 120 & Lumbrinereis sp. & 1 & 0 \\
\hline Cnidaria & & & Glyceridae sp. & 1 & 0 \\
\hline Hydrozoa sp. 1 & 1 & 1 & Hesionidae spp. & 3 & 1 \\
\hline Hydrozoa sp. 2 & 1 & 0 & Nereis sp. & 1 & 0 \\
\hline Hydrozoa sp. 3 & 1 & 0 & Polynoidea (damaged) & 3 & 2 \\
\hline Hydrozoa sp. 4 & 0 & 1 & Polynoidea sp. 1 & 1 & 0 \\
\hline Hydrozoa sp. 5 & 1 & 0 & Polynoidea sp. 3 & 0 & 1 \\
\hline Hydrozoa sp. 6 & 1 & 0 & Sabellidae sp. & 0 & 1 \\
\hline Keratoisis sp. & 1 & 1 & Maldanidae sp. & 1 & 1 \\
\hline Actinaria sp. 1 & 1 & 1 & Capitellidae sp. & 0 & 1 \\
\hline Actinaria sp. 2 & 1 & 1 & Orbiniidae sp. & 4 & 1 \\
\hline 'Keratoisis anemone' & 1 & 1 & Spionidae sp. & 5 & 3 \\
\hline Edwardsia sp. & 0 & 1 & Terebellidae sp. & 0 & 5 \\
\hline Brachiopoda & & & Amphisamytha sp.* & 3 & 1 \\
\hline Brachiopoda sp. & 1 & 0 & Arthropoda & & \\
\hline Mollusca & 0 & 0 & Lohmannellinae sp. & 1 & 0 \\
\hline Solengastres sp. & 8 & 1 & Pycnogonida sp. & 1 & 0 \\
\hline Gastropoda sp. 1 & 0 & 2 & Copepoda spp. & 2 & 5 \\
\hline Gastropoda sp. 2 & 0 & 1 & Harpactacoid copepod sp. & 0 & 1 \\
\hline Gastropoda sp. 3 & 0 & 1 & Scalpellomorph sp. 1 & 0 & 1 \\
\hline Gastropoda sp. 4 & 0 & 1 & Scalpellomorph sp. 2 & 1 & 0 \\
\hline Gastropoda sp. 5 & 1 & 0 & Trianguloscalpellum & 1 & 0 \\
\hline Gastropoda sp. 6 & 1 & 0 & michelottanum & & \\
\hline Philine sp. & 1 & 0 & Vulcanolepas parensis & 53 & 9 \\
\hline Diaphana sp. & 0 & 2 & Glyptelasma sp. & 0 & 1 \\
\hline Neomphalid n. gen. & 0 & 1 & Poecilasma kaempferi & 8 & 6 \\
\hline Lepetodrilus schrolli* & 2 & 44 & Altiverruca sp. & 26 & 12 \\
\hline Anatoma sp. & 3 & 1 & Eurodella sp. & 0 & 1 \\
\hline Olgasolaris tollmani* & 3 & 1 & Tanaidacea spp. & 1 & 2 \\
\hline Shinkailepas sp.* & 2 & 1 & Isopod sp. 1 & 1 & 3 \\
\hline Eosipho juvenile $^{*}$ & 2 & 0 & Isopod sp. 2 & 2 & 2 \\
\hline Alviniconcha juvenile* & 1 & 0 & Isopod sp. 3 & 3 & 0 \\
\hline Desbruyeresia sp. ${ }^{*}$ & 5 & 0 & Isopod sp. 4 & 0 & 1 \\
\hline Provanna sp. & 0 & 1 & Amphipod indet. (damaged) & 0 & 1 \\
\hline Vitrinellidae sp. & 0 & 9 & Amphipod sp. 1 & 3 & 7 \\
\hline Nuculanoidea n. gen., n. sp. & 3 & 6 & Amphipod sp. 2 & 23 & 42 \\
\hline Bivalvia sp. 1 & 0 & 1 & Amphipod sp. 3 & 0 & 1 \\
\hline Thyasiridae sp. 1 & 4 & 16 & Amphipod sp. 4 & 0 & 1 \\
\hline Nemertea & & & Amphipod sp. 5 & 1 & 0 \\
\hline Nemeretea sp. & 1 & 0 & Amphipod sp. 6 & 6 & 0 \\
\hline Platyhelminthes & & & Lysianassidae sp. 1 & 2 & 0 \\
\hline Platyhelminthes sp. & 1 & 0 & Lysianassidae sp. 2 & 1 & 0 \\
\hline Sipuncula & 0 & 0 & Mysidacea spp. & 1 & 0 \\
\hline Sipuncula sp. & 1 & 0 & Nematocarcinus sp. & 2 & 0 \\
\hline Echinodermata & & & Alvinocarididae sp. ${ }^{*}$ & 0 & 1 \\
\hline Ophiura sp. 1 & 0 & 1 & Chorocaris sp.* ${ }^{*}$ & 3 & 0 \\
\hline Ophiura sp. 2 & 4 & 1 & Anomura sp. & 0 & 1 \\
\hline Crinoidea sp. & 1 & 0 & Munida magniantennulata & 4 & 2 \\
\hline Holothurian sp. & 1 & 0 & Munidopsis lauensis* & 4 & 18 \\
\hline \multicolumn{6}{|l|}{ Annelida } \\
\hline Echiura sp. & 1 & 0 & Total no. of taxa & 65 & 58 \\
\hline Archinome sp. ${ }^{*}$ & 1 & 0 & Total no. of individuals & 402 & 354 \\
\hline
\end{tabular}

as abundant at South Su than Solwara 1. In contrast Alviniconcha spp., Olgasolaris tollmanni, Branchintogluma trifurcus and Ifremeria nautilei were almost twice as abundant at Solwara 1 than at South Su.
Within-site similarities were driven by relative abundances of just a few taxa (Table 7), including the taxa that dominated each assemblage type (i.e. Alviniconcha spp., I. nautilei, Eochionelasmus ohtai). 
Table 3. Sufficiency of the sampling effort for each assemblage at each site as calculated by ratio of standard error (SE) of the mean to arithmetic mean. Inadequate sampling effort in bold

\begin{tabular}{|c|c|c|c|c|c|}
\hline Variable & Site & Assemblage & Mean & SE mean & SE mean/Mean (\%) \\
\hline \multirow[t]{8}{*}{ Total no. of individuals } & Solwara 1 & Alviniconcha & 75.20 & 18.60 & 24.73 \\
\hline & South Su & Alviniconcha & 199.70 & 66.10 & 33.10 \\
\hline & Solwara 1 & Eochionelasmus & 253.30 & 44.70 & 17.65 \\
\hline & South $\mathrm{Su}$ & Eochionelasmus & 281.20 & 45.50 & 16.18 \\
\hline & Solwara 1 & Ifremeria & 480.10 & 84.00 & 17.50 \\
\hline & South Su & Ifremeria & 1467.00 & 236.00 & 16.09 \\
\hline & Solwara 1 & Peripheral & 27.80 & 8.28 & 29.78 \\
\hline & South $\mathrm{Su}$ & Peripheral & 28.54 & 9.32 & 32.66 \\
\hline \multirow[t]{8}{*}{ Total no. of taxa } & Solwara 1 & Alviniconcha & 6.89 & 1.15 & 16.69 \\
\hline & South Su & Alviniconcha & 7.89 & 1.12 & 14.20 \\
\hline & Solwara 1 & Eochionelasmus & 5.33 & 0.47 & 8.83 \\
\hline & South Su & Eochionelasmus & 6.89 & 0.89 & 12.90 \\
\hline & Solwara 1 & Ifremeria & 7.44 & 0.65 & 8.70 \\
\hline & South Su & Ifremeria & 9.78 & 0.78 & 7.96 \\
\hline & Solwara 1 & Peripheral & 8.67 & 1.83 & 21.11 \\
\hline & South $\mathrm{Su}$ & Peripheral & 8.00 & 1.90 & 23.75 \\
\hline \multirow[t]{5}{*}{ Shannon diversity } & Solwara 1 & Alviniconcha & 1.24 & 0.12 & 10.01 \\
\hline & South Su & Alviniconcha & 1.16 & 0.07 & 6.05 \\
\hline & Solwara 1 & Eochionelasmus & 0.67 & 0.09 & 14.07 \\
\hline & South Su & Eochionelasmus & 0.89 & 0.08 & 9.44 \\
\hline & Solwara 1 & Ifremeria & 1.39 & 0.05 & 3.63 \\
\hline
\end{tabular}

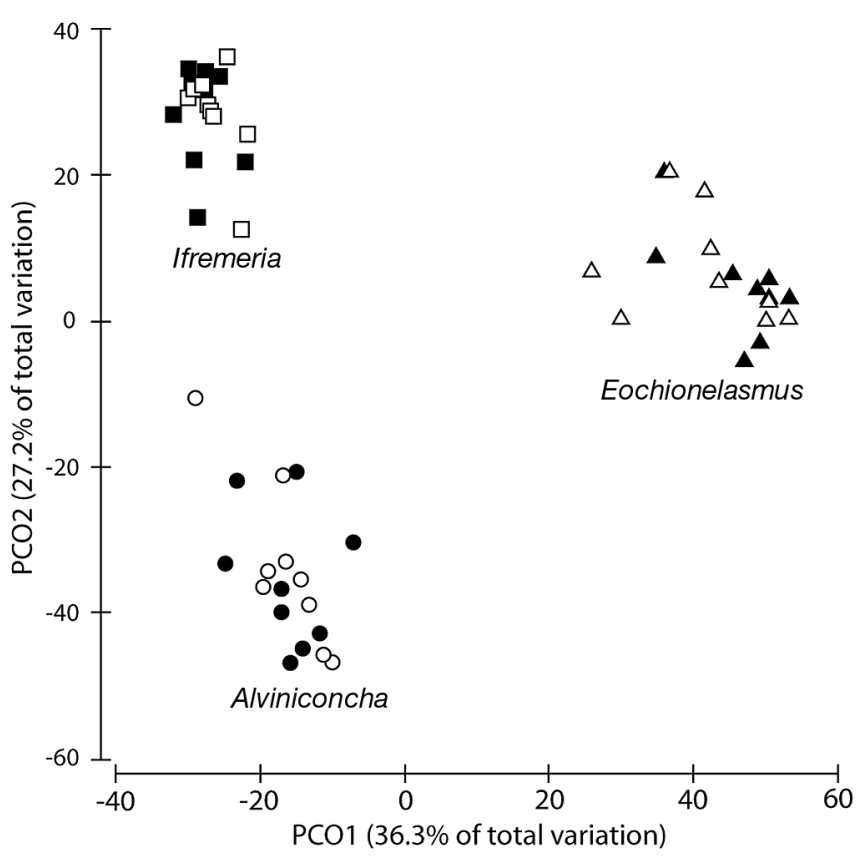

Fig. 3. Comparison of site and assemblage similarities (Bray-Curtis) using dispersion-weighted abundance data from active vents in a principal coordinates ordination (PCO). The model explains $63.5 \%$ of the variation in the data sets. Filled symbols: Solwara 1; open symbols: South Su. Assemblages: $(\bullet, 0)$ Alviniconcha; $(\mathbf{\square}, \square)$ Ifremeria; $(\boldsymbol{\Lambda}, \Delta)$ Eochionelasmus

\section{Community similarity, peripheral vent environment}

There was no significant difference between presence-absence samples of peripheral assemblages at Solwara 1 and South Su (PERMANOVA, $\mathrm{p}>0.05)$.

\section{Combined active vent and vent periphery multivariate analyses}

PCO plots derived from similarity matrices (presence-absence data; Fig. 4) suggest 4 assemblages (Alviniconcha, Ifremeria, Eochionelasmus and vent periphery) with no differentiation by site. Pairwise tests showed all assemblages were different $(\mathrm{p}<0.001)$.

This is consistent with PERMANOVA results (Table 8), where there was a significant difference ( $p=0.001)$ in composition at the level of assemblage, but no significant difference in compostion at the site level, between Solwara 1 and South Su.

Average dissimilarity between active vent and vent peripheral samples was high, >90\% (Table 9). Of the taxa contributing most to the taxonomic differentiation of samples from each habitat type, 4 were exclusively 
Table 4. Alviniconcha, Ifremeria and Eochionelasmus assemblages. Taxa contributing $>5 \%$ to dissimilarities between assemblages at active vents (Solwara 1 and South Su data combined) determined by similarity percentages (SIMPER) analysis using dispersion-weighted abundances. Average dissimilarity between Eochionelasmus and Ifremeria: $91 \%$; Eochionelasmus and Alviniconcha: 98\%; Ifremeria and Alviniconcha: $88 \%$

\begin{tabular}{|c|c|c|c|c|}
\hline \multirow[t]{2}{*}{ Taxon } & \multicolumn{2}{|c|}{ Average abundance $\mathrm{C}$} & Contribution & \multirow{2}{*}{$\begin{array}{c}\text { Cumulative } \\
(\%)\end{array}$} \\
\hline & emblage 1 & Assemblage 2 & & \\
\hline \multicolumn{2}{|c|}{ Eochionelasmus } & \multicolumn{2}{|l|}{ Ifremeria } & \\
\hline Eochionelasmus ohtai & 7.6 & 0.1 & 29 & 29 \\
\hline $\begin{array}{l}\text { Branchinotogluma } \\
\text { trifurcus }\end{array}$ & 0.0 & 3.7 & 13 & 43 \\
\hline $\begin{array}{l}\text { Amphisamytha } \\
\text { cf. galapagensis }\end{array}$ & 1.1 & 3.9 & 11 & 54 \\
\hline Olgasolaris tollmanni & 0.0 & 2.9 & 10 & 64 \\
\hline Ifremeria nautilei & 0.0 & 2.4 & 9 & 73 \\
\hline Lepetodrilus schrolli & 0.2 & 2.2 & 8 & 81 \\
\hline \multicolumn{4}{|c|}{ Eochionelasmus Alviniconcha } & \\
\hline Eochionelasmus ohtai & 7.6 & 0.0 & 45 & 45 \\
\hline Alviniconcha spp. & 0.0 & 2.2 & 14 & 59 \\
\hline \multirow{2}{*}{$\begin{array}{l}\text { Amphisamytha } \\
\text { cf. galapagensis }\end{array}$} & 1.1 & 0.1 & 7 & 66 \\
\hline & Ifremeria & Alviniconcha & & \\
\hline $\begin{array}{l}\text { Amphisamytha } \\
\text { cf. galapagensis }\end{array}$ & 3.9 & 0.1 & 18 & 18 \\
\hline $\begin{array}{l}\text { Branchinotogluma } \\
\text { trifurcus }\end{array}$ & 3.7 & 0.2 & 16 & 35 \\
\hline Olgasolaris tollmanni & 2.9 & 0.2 & 12 & 47 \\
\hline Alviniconcha spp. & 0.2 & 2.2 & 11 & 57 \\
\hline Ifremeria nautilei & 2.4 & 0.3 & 10 & 68 \\
\hline Lepetodrilus schrolli & 2.2 & 0.2 & 10 & 77 \\
\hline
\end{tabular}

Table 5. Spatial variability on dispersion-weighted taxaabundance similarity (Bray-Curtis) matrices between sites, mounds, and assemblages at active vents as determined with a nonparametric 3-way nested permutational multivariate analysis of variance (PERMANOVA) using Site ( $\mathrm{Si})$, Mound (Mo), and Assemblage (As) as random factors. Significant values $(\mathrm{p}<0.05)$ in bold. ns: not significant $(\mathrm{p}>$ 0.05); Pseudo-F: null hypothesis distribution; $\mathrm{p}($ perm): $\mathrm{p}$-values obtained using permutations; perm: number of permutable units; $\mathrm{p}(\mathrm{MC})$ : $\mathrm{p}$-values obtained using Monte Carlo simulations

\begin{tabular}{|lcccccc|}
\hline Source & df & MS & Pseudo-F & p(perm) & perm & p(MC) \\
\hline $\mathrm{Si}$ & 1 & 4500.7 & 3.64 & $\mathrm{~ns}$ & 10 & $\mathbf{0 . 0 0 1 9}$ \\
$\mathrm{Mo}(\mathrm{Si})$ & 4 & 1218.4 & 0.14 & $\mathrm{~ns}$ & 9927 & $\mathrm{~ns}$ \\
As(Mo(Si)) & 12 & 8692.7 & 9.13 & $\mathbf{0 . 0 0 0 1}$ & 9880 & $\mathbf{0 . 0 0 0 1}$ \\
Residual & 36 & 952.0 & & & & \\
Total & 53 & & & & & \\
\hline
\end{tabular}

found at active vents (Ifremeria nautilei, Alviniconcha spp., Eochionelasmus ohtai, Branchinotogluma trifurcus) and 2 (hydroids and the anemone associated with Keratoisis) were exclusive to the vent periphery.

\section{Qualitative observations}

Qualitative samples and observations provided additional information on the composition of the biota at Solwara 1 and South Su. At both sites shrimp (Chorocaris spp.), brachyuran crabs (Austinograea sp.), and 3 taxa of polynoid scale worms (Branchinotogluma trifurcus, Thermopolynoe branchiata, $B$. segonzaci) were associated with Alviniconcha and Ifremeria assemblages. Squat lobsters Munidopsis lauensis, shrimp (Lebbeus spp., Alvinocaris sp. and Nematocarcinus sp.), brachyuran crabs (Austinograea sp.) and small clumps of stalked barnacles (Vulcanolepas sp.) were associated with Eochionelasmus habitats. Pyrolycus manusanus (Fig. 5), a ventendemic zoarcid eelpout (Machida \& Hashimoto 2002), was common at Solwara 1 and South Su.

Mobile predators, such as the fish Lepidion schmidti and Hexatrygon bickelli, and the octopus Benthoctopus sp. were observed close to active vents at both sites. The giant sea spider Collossendeis sp., the benthic ctenophore Tjalfiella tristoma, the hermit crab Parapagurus richer, and fish such as Congridae sp., Halosauridae sp., Ophidiidae sp., Rhinochimaera pacifica and Hydrolagus trolli were observed in the vicinity of inactive sulphide mounds at both sites. In sedimented areas at the base of chimneys at both sites, there were large numbers of the echiuran Alomasoma belyaevi (Fig. 5) and of an unidentified bivalve in the Nuculanoidea grouping. Predatory buccinid gastropods (Eosipho sp.) were observed in small numbers around the base of vents.

South Su hosted mussels (Bathymodiolus manusensis), tubeworm aggregations (Alaysia n. sp., Arcovestia ivanovi), and solitary tubeworms (Lamellibrachia sp.). In some places, dense crusts of neomphalid limpets were observed (Fig. 5). Other patches of organisms presumed to rely on chemosynthetic microbial symbioses were observed in the vicinity of the active vents at South Su only, including beds of large bivalves (10 cm long; Conchochele sp.) and beds of an unknown polychaete resembling a paralvinellid type worm. Similar chemosynthetic assemblages were not observed at Solwara 1 despite rigorous visual assessment. 
Table 6 . Taxa contributing $>5 \%$ to dissimilarity between Solwara 1 and South $\mathrm{Su}$ as determined with similarity percentages (SIMPER) analysis calculated from dispersion-weighted faunal abundance matrices, active vents. Average dissimilarity between sites was $80 \%$

\begin{tabular}{|c|c|c|c|c|}
\hline \multirow[t]{2}{*}{ Taxon } & \multicolumn{2}{|c|}{ Average abundance } & \multirow{2}{*}{$\begin{array}{c}\text { Contribution } \\
(\%)\end{array}$} & \multirow{2}{*}{$\begin{array}{c}\text { Cumulative } \\
(\%)\end{array}$} \\
\hline & Solwara 1 & South Su & & \\
\hline Eochionelasmus ohtai & 2.8 & 2.4 & 22 & 22 \\
\hline $\begin{array}{l}\text { Amphisamytha cf. } \\
\text { galapagensis }\end{array}$ & 1.9 & 1.5 & 11 & 34 \\
\hline $\begin{array}{l}\text { Branchinotogluma } \\
\text { trifurcus }\end{array}$ & 1.7 & 0.8 & 9 & 43 \\
\hline Alviniconcha spp. & 1.1 & 0.5 & 9 & 52 \\
\hline Olgasolaris tollmanni & 1.3 & 0.7 & 7 & 59 \\
\hline Lepetodrilus schrolli & 0.2 & 1.5 & 7 & 66 \\
\hline Ifremeria nautilei & 1.1 & 0.6 & 6 & 72 \\
\hline
\end{tabular}

Table 7. Taxa contributing to $>10 \%$ similarity within Solwara 1 and South Su calculated from dispersion-weighted faunal abundance matrices, active vents. Average similarity, Solwara 1: $21 \%$; South $\mathrm{Su}: 22 \%$

\begin{tabular}{|lcccc|}
\hline Taxon by site & $\begin{array}{c}\text { Average } \\
\text { abundance }\end{array}$ & $\begin{array}{c}\text { Average } \\
\text { similarity (\%) }\end{array}$ & $\begin{array}{c}\text { Contribution } \\
(\%)\end{array}$ & $\begin{array}{c}\text { Cumulative } \\
(\%)\end{array}$ \\
\hline Solwara 1 & & & & \\
$\quad$ Eochionelasmus ohtai & 2.8 & 5.3 & 25 & 25 \\
$\quad \begin{array}{l}\text { Alviniconcha spp. } \\
\text { Amphisamytha cf. }\end{array}$ & 1.1 & 4.1 & 20 & 45 \\
$\quad 1.9$ & 4.0 & 19 & 64 \\
$\quad$ galapagensis & & & & \\
$\begin{array}{l}\text { South Su } \\
\text { Eochionelasmus ohtai }\end{array}$ & 2.4 & 4.7 & 21 & 21 \\
$\quad \begin{array}{l}\text { Amphisamytha cf. } \\
\text { galapagensis }\end{array}$ & 1.5 & 4.4 & 20 & 41 \\
$\quad$ Lepetodrilus schrolli & 1.5 & 3.4 & 15 & 56 \\
\hline
\end{tabular}

\section{DISCUSSION}

This study describes the ecological assessment of a proposed mining development at a hydrothermal vent habitat in a tectonically active region. There are many potential ecological impacts of this proposed development as outlined above (see 'Effects of mining and mitigation') and elsewhere (Gwyther 2008, Van Dover 2011). The main focus of the study is to assess the suitability of South $\mathrm{Su}$ to act as a reference plot from which the hydrothermal-vent community can repopulate Solwara 1.

Manus Basin vents are characterized by 3 visually identifiable biogenic habitats, namely clusters of 2 taxa of endosymbiont-hosting provannid snails (Alviniconcha spp. and Ifremeria nautilei), and encrustations of the sessile barnacle Eochionelasmus ohtai. There is also a peripheral fauna colonizing inactive sulfide mounds, where Keratoisis sp. bamboo coral is a characteristic element. In these regards, Manus Basin vents share similarities with other vent systems of the Southwest Pacific (North Fiji, Lau Basins, Okinawa, Mariana; Desbruyères et al. 2006). Applications for exploration licenses have been lodged in both Fiji and Lau Basins.The general approach and findings described here can inform baseline studies in these areas. The dominant taxa are, by their vent endemic nature, robust to chemical disturbance. From studies in Lau Basin, Alviniconcha spp. are known to be associated with the highest temperature and sulfide concentrations (Podowski et al. 2009), with a high demand for and tolerance to sulfide (Henry et al. 2008). I. nautilei have similar thermal tolerances to those of Alviniconcha spp., while E. ohtai occupy near ambient temperature conditions outside the clusters of snails.

The multiplicity of biogenic habitats and their associated physicochemical environments motivated quantitative assessment of community structure using a replicated $(3 \times)$, nested sampling design, with assemblage (Alviniconcha, Ifremeria, Eochionelasmus) nested within mound $(\times 3)$, nested within site (Solwara 1 or South $\mathrm{Su}$ ). Very short spatial scales of habitat diversity (patches on the order of $1 \mathrm{~m}$ or less) required use of a remotely operated vehicle for precision sample collection. The nested design provides more insight into how communities vary with habitat and permits tests of hypotheses about habitat differences in community structure. These kinds of studies are becoming more common for biogenic assemblages in the deep sea (e.g. mussel beds: Dreyer et al. 2005; tubeworm clumps: Govenar et al. 2005). The abundance and biomass of macroand megafaunal invertebrates at active vents allowed for quantitative sampling and analysis, but peripheral vent samples, where faunal abundances were low, were semi-quantitative, with opportunity only to compare between sites and with many taxa tallied by presence or absence within samples.

Van Dover (2010) suggests that lessons learned and best management practices from coastal studies should be applied to the deep-sea. In terms of sampling effort, coastal studies suggest that the number or proportion of singleton species does not decrease with increased sample replication. For example, 


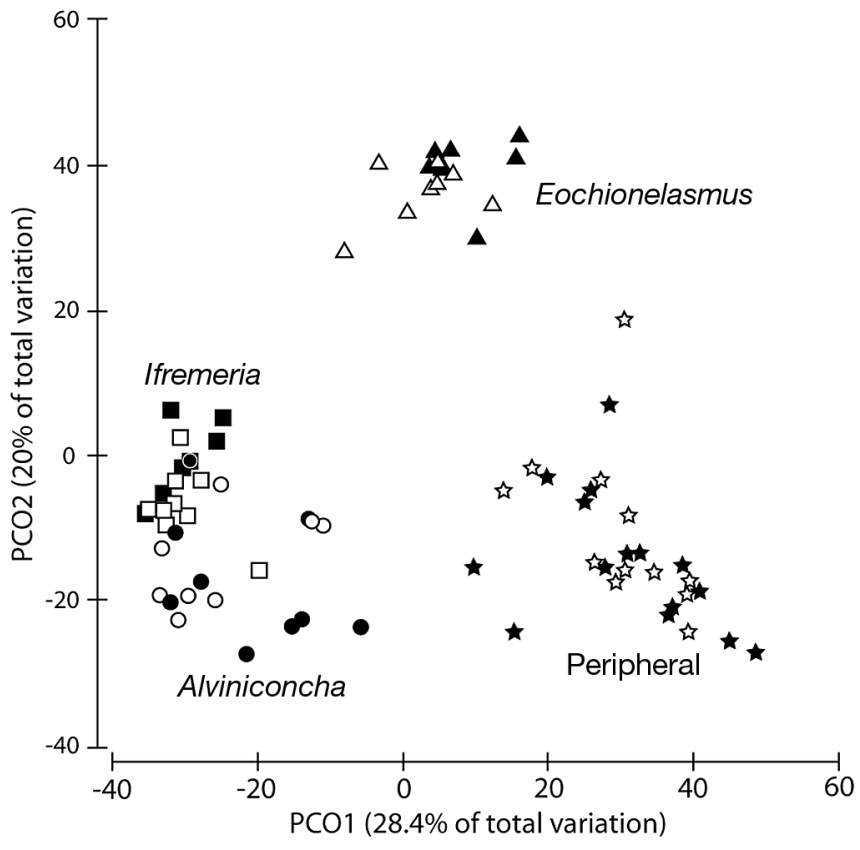

Fig. 4. Comparison of site and assemblage similarities (BrayCurtis) using presence-absence data from active vent assemblages and vent periphery in a principal coordinates ordination (PCO). The model explains $48.4 \%$ of the variation in the data sets. Filled symbols: Solwara 1; open symbols: South Su. Assemblages: $(\bullet, \bigcirc)$ Alviniconcha; $(\boldsymbol{\square}, \square)$ Ifremeria; $(\boldsymbol{\Lambda}, \Delta)$ Eochionelasmus; $(\star, \hbar)$ vent periphery

Rumohr et al. (2001) collected 70 benthic replicates from a soft sediment station and found that 5 replicates accounted for only $53 \%$ of the species present, and that the number of species in 70 samples would only account for a fraction of the number of species in 100 to 200 samples. Coastal ecologists consider it unrealistic to design a survey that includes all of species in a system (Rumohr et al. 2001, Gray 1984). To minimize cost and labour they standardize their sampling effort to achieve a standard error for species richness equal to $20 \%$ of the sample mean (Elliott 1977).

Table 8. Comparison of merged data sets (active vent and vent peripheral Bray-Curtis similarity; presence-absence data); 2-factor permutational multivariate analysis of variance (PERMANOVA) with Site (Si) and Assemblage $($ As) as random factors.. Significant values $(p<0.05)$ in bold. ns: not significant ( $p>0.05)$; Pseudo-F: null hypothesis distribution; $\mathrm{p}(\mathrm{perm})$ : $\mathrm{p}$-values obtained using permutations; perm: number of permutable units; $\mathrm{p}(\mathrm{MC})$ : $\mathrm{p}$-values obtained using Monte Carlo simulations

\begin{tabular}{|lccccccc|}
\hline Source & df & SS & MS & Pseudo- $F$ & p(perm) & perm & p(MC) \\
\hline Site & 1 & 2964 & 2964 & 0.19 & ns & 921 & ns \\
As(Si) & 6 & 95093 & 15849 & 11.30 & $\mathbf{0 . 0 0 1}$ & 998 & $\mathbf{0 . 0 0 1}$ \\
Residual & 74 & $1.04 \mathrm{E}+05$ & 1403 & & & & \\
Total & 81 & $2.02 \mathrm{E}+05$ & & & & & \\
\hline
\end{tabular}

One of the common characteristics of vent communities is the presence of taxa with strongly clustered spatial distributions. Lepetodrilus schrolli in Manus Basin samples reported here is a good example; within Alviniconcha assemblage samples at Solwara 1 mean abundance was 70 individuals per sample, with a standard deviation of 106 and a range from 0 to 423 individuals. Down-weighting taxa counts where independent replicates exhibit clustering reduces noise in the analysis without compromising the ability to detect signal differences (Clarke et al. 2006).

Significant differences in community structure of active vents were observed among assemblages nested within mounds and sites using multivariate approaches (taxon-abundance matrices), but not among mounds nested by site. We interpret this as evidence that physico-chemical environmental differences that influence the abundance of the biogenic taxa also influence the composition and abundance of the associated macrofauna and that these environments defined by the biogenic taxa are comparable from one mound to another (Luther et al. 2001). When only presenceabsence data were used (faunal composition, without information on relative abundances), 4 distinct assemblages were apparent: Alviniconcha, Ifremeria, Eochionelasmus, and vent peripheral.

Multivariate differentiation of community structure at South Su and Solwara 1 was dependent on the method of obtaining p-values, with the Monte Carlo simulation, which involves generation of 'new' data under the null hypothesis rather than resampling, yielding a signifcant difference. Site differences for vent assemblages situated just a few kilometers apart are now well documented and have been correlated with factors such as the age of the biogenic habitat that defines the assemblage (e.g. Van Dover 2003, Dreyer et al. 2005). Multivariate analyses indicated that peripheral vent fauna of Solwara 1 and South Su samples were well differentiated from the active vent assemblages (presence-absence data). There were a number of taxa that crossed the 'peripheral-active' boundary, but taxa known to host chemoautotrophic endosymbionts were restricted to active vents. Site was not a significant factor when presenceabsence matrices were analyzed.

One of the goals of this study was to determine whether Solwara 1, a site proposed for mineral extraction, and South $\mathrm{Su}$, a designated reference area, shared the same taxa pool. While each site has a number of very 
Table 9. Taxa contributing to $50 \%$ of the cumulative dissimilarity between vent peripheral and active vent samples, calculated from presence-absence matrices. Average dissimilarity was $94 \%$. Taxa found exclusively in either active or peripheral vent samples in bold

\begin{tabular}{|lcccc|}
\hline Taxon & $\begin{array}{c}\text { Average abundance } \\
\text { Active }\end{array}$ & $\begin{array}{c}\text { Contribution } \\
(\%)\end{array}$ & $\begin{array}{c}\text { Cumulative } \\
(\%)\end{array}$ \\
\hline $\begin{array}{l}\text { Lepetodrilus schrolli } \\
\text { Amphisamytha cf. }\end{array}$ & 0.89 & 0.21 & 6 & 6 \\
$\quad$ galapagensis & 0.70 & 0.11 & 6 & 12 \\
Olgasolaris tollmanni & 0.59 & 0.11 & 4 & 16 \\
Ifremeria nautilei & 0.56 & 0 & 4 & 20 \\
Chorocaris sp. & 0.54 & 0.11 & 4 & 25 \\
Branchinotogluma & 0.48 & 0 & 4 & 28 \\
$\quad$ trifurcus & & & & 32 \\
Alviniconcha spp. & 0.44 & 0 & 4 & 36 \\
Eochionelasmus ohtai & 0.41 & 0 & 4 & 42 \\
Keratoisis sp. & 0.02 & 0.43 & 4 & 45 \\
$\quad \begin{array}{l}\text { Vulcanolepas parensis } \\
\text { Abyssocladia sp. }\end{array}$ & 0.30 & 0.18 & 3 & 51 \\
Hydrozoa sp. 1 & 0.04 & 0.43 & 3 & \\
Anemone (Keratoisis & 0 & 0.43 & 3 & \\
$\quad$ associate) & 0 & 0.32 & 3 & \\
\hline
\end{tabular}

thority 2010; www.isa.org.jm/en/documents/mcode) offers no criteria for establishment of PRZs where no mineral extraction will occur. At a minimum, extraction sites and PRZ sites must support the same biomass-dominant taxa, have similar community structure, and have at least the same diversity of habitats or biogenic assemblages. If PRZs are to serve as brood stock to repopulate disturbed vent areas, hydrographic conditions and larval behaviours must be such that there is potential for larval transport and recruitment to the extraction site from the PRZ. Another criterion for suitability of a PRZ might be shared genetic diversity within populations at sites to be extracted and those designated as PRZs. Populations that are genetically differentiated are isolated from one another (reviewed

rare taxa not observed at the other site, the dominant biogenic assemblages are shared and for a given assemblage, there were no significant site differences when only presence-absence data are used. Though some of the less abundant South Su species were absent from Solwara 1, there is no way to determine from our sampling whether potential colonizers occur in adjacent areas or whether these species play any special functional role within the South Su site.

As comprehensive as this sampling design undertaken here may seem, nested sampling of shared assemblages failed to capture important elements of site-specific differences, including the presence of additional biogenic taxa (and chemoautotrophic symbiont-hosting invertebrates) at South Su that were not present at Solwara 1, namely mussels (Bathymodiolus manusensis) and tubeworms (Alaysia sp., Arcovestia ivanovi, Lamellibrachia sp.). This points to the value of opportunistic observations to capture critical features of a landscape. That South Su includes additional taxa of interest (i.e. taxa that host autotrophic endosymbionts) adds to its suitability as a source of brood stock. South Su populations have the potential to repopulate Solwara once extraction ceases, assuming suitable sulfide habitats reform. Populations of peripheral areas of the South Su field will also contribute to repopulation of Solwara 1 peripheral area.

South $\mathrm{Su}$ is a reference site in Papua New Guinea's territorial waters and is an analogue to Preservation Reference Zones (PRZs) in international waters. The international Mining Code (International Seabed Au- by Hellberg 2009); this is not a condition consistent with a brood stock value for a PRZ. On-going comparative studies of genetic diversity of indicator species at Solwara 1 and South Su suggest that gene flow in several taxa is infinite between Solwara 1 and South $\mathrm{Su}$, providing further support for the suitability of South $\mathrm{Su}$ as a reference site (A. Thaler unpubl.).

Modelling the potential of one discrete site to effectively repopulate another site requires an understanding of hydrographic flow between the sites. In the baseline survey for this project (Gwyther 2008) extensive oceanographic measurements of current velocities and water column stratification were available with which to determine the path of entrained particles from South Su to Solwara 1. Assuming that larvae can be modelled as passive particles, simply modelling current flow provides an initial estimate of gene flow. More developed modelling at carbonate seamounts (Lavelle \& Mohn 2010) using a larval transport Lagrangian model has demonstrated the role of active and passive larval dispersal modes in determining species connectivity and distribution in relation to hydrography. Similar models at hydrothermal vent communities would improve our understanding of the effectiveness of reference plots.

Environmental baselines at hydrothermal vents need not be limited to analyses of macrofaunal invertebrate community structure (Juniper 2004, Van Dover 2007). The extent to which macrofaunal data sets serve as proxies for microbial or meiofaunal community structure or other parameters of interest 

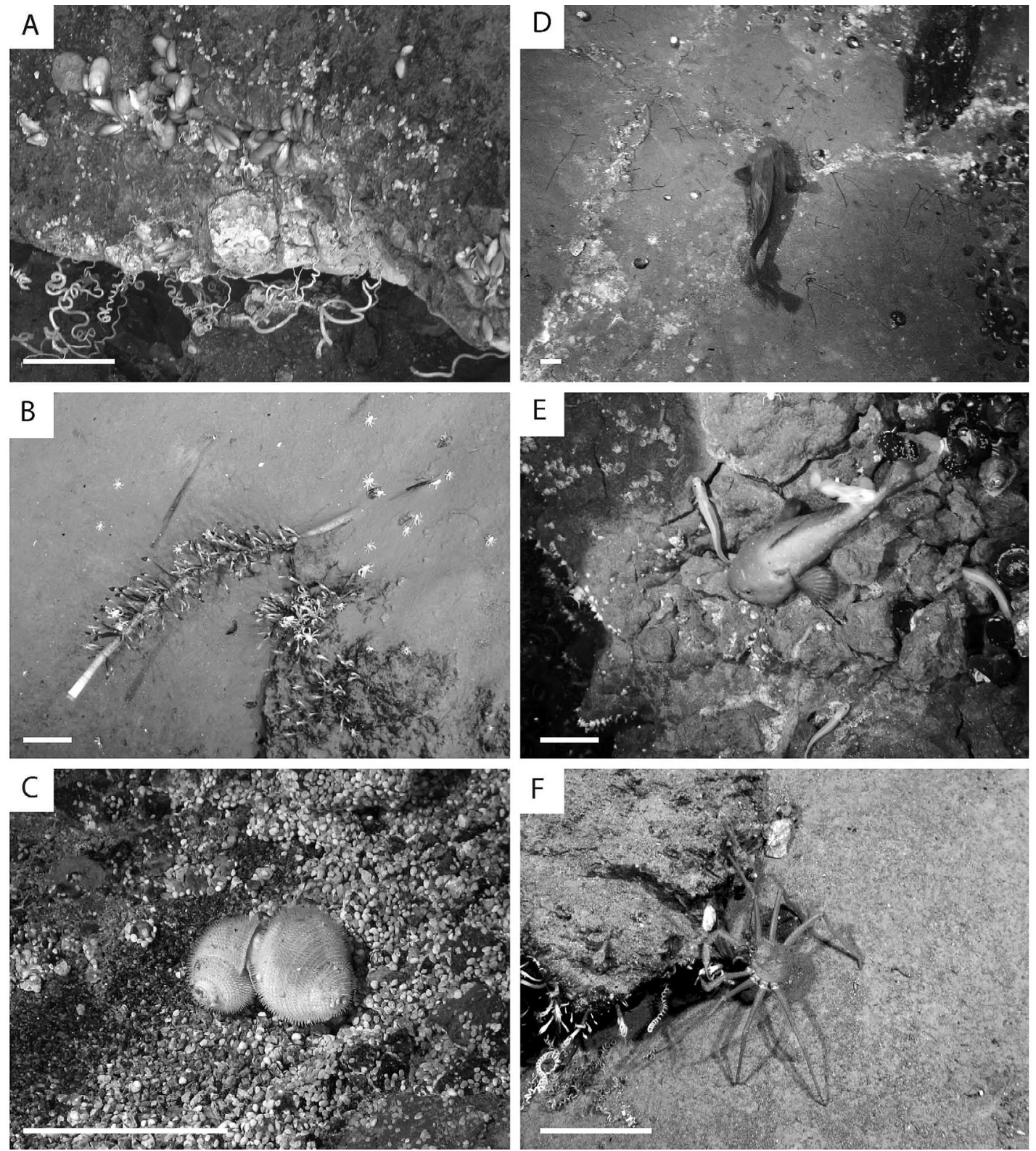

Fig. 5. Qualitative observations. (A) Mussels (Bathymodiolus manusensis) and tubeworms (Alaysia sp., Arcovestia lauensis), (B) Solitary tubeworm Lamellibrachia sp. with stalked barnacles Vulcanolepas parensis, (C) Alviniconcha sp. on a crust of limpets, (D) Gray hake on a bed of echiuran worms (Alomasoma belyaevi), (E) (center) Blob sculpin Psychrolutes marcidus with eelpout Pyrolycus manusanus, (F) Lithodid crab (Paralomis sp.) feeding on $V$. parensis with coiled tubeworm Alaysia sp. scale bars $=10 \mathrm{~cm}$. Images courtesy of Nautilus Minerals

is likely limited. For example, meiofaunal patterns of abundance, diversity, and distribution at vents on the East Pacific Rise were very different from those of vent macrofauna (Gollner et al. 2010) and microbial diversity is likely exquisitely linked to geochemistry (e.g. Wang et al. 2009). Other baseline elements are important, including detailed maps of the distribution of active or inactive vents and other hard substrata within the zone likely to be influenced by extraction, trophic studies, and genetic analysis of key or indicator species to determine whether there is evidence for local population structure (Van Dover 2007). From this kind of comprehensive baseline data, one can optimize disturbance patterns to minimize environmental impact and monitor and assess the dynamics of recovery after cessation of activities.

Certain taxa are endemic to active vent habitats in Manus Basin, where they are abundant and occur in 
dense, easily observed patches, and serve as biogenic habitats for distinct assemblages of other species. These include Alviniconcha spp., Ifremeria nautilei, and Eochionelasmus ohtai, which are expected to be fast-growing and opportunistic taxa that readily recruit to vent systems (Henry et al. 2008). As such, these taxa are useful for comparison of what happens in a disturbed location compared with what happens in several control/reference and undisturbed locations using an asymmetrical analysis (Underwood 1997), with either visual or quantitative sampling. There is no equivalent taxon for rapid assessment using modified asymmetrical designs for vent peripheral samples. While some taxa in the vent periphery are large (e.g. Keratoisisi sp.), they are sparsely distributed and have slow growth rates (Andrews et al. 2009), making assessing their recovery difficult. The peripheral areas will contribute to repopulation; however the non-site specific fauna are likely to be variable over time. We know that neither the impacted nor the control site will be the same after a number of years.

The balanced survey design used here establishes a baseline against which recovery of active vent assemblages and vent peripheral assemblages may be compared. The contagious distribution of taxa calls for dispersion-weighted data and parametric statistical analyses. A still more complete analysis would undertake measures of community structure replicated over time both before and after extraction activities begin to allow assessment of interactions between location and time even when there is no disturbance (Stewart-Oaten et al. 1986). Sampling must follow the guidleines outlined by the Interridge statement of commitment to responsible research practices at deep sea hydrothermal vents (Devey et al. 2007).

While the approach used here establishes a quantitative baseline for natural spatial variation in vent assemblages, it would be useful for impact assessment to add a temporal component of community structure analysis prior to extractive activities to test for interactions between location and time in the absence of disturbance (Underwood 1997). In this study, natural variability in relation to hydrothermal venting and tectonic activity is very high. The nature of spatial variability at a fixed point in time has been quantified, but temporal variability within Solwara 1 and South Su has not been addressed. The logistical and cost considerations of this type of work will prohibit repeated baseline surveys in most proposed developments. The establishment of sentinel sites at hydrothermal vents, across biogeographic regions, to assess the nature of temporal variability in these communities would be of great value.
Acknowledgements. Nautilus Minerals provided financial support for fieldwork and shore-based analyses. The at-sea component of the effort was made possible through the professional efforts of the captain and crew of Global Marine's CS 'Wave Mercury', the UTEC survey staff, the Helix Offshore staff, the operators of the ROV, and Nautilus Minerals personnel, especially S. Smith. Samples were analyzed on behalf of the people of Papua New Guinea. M. Mungkaje assisted with data analysis as a Nautilus Minerals supported bursary scholar from Papua New Guinea at the Duke University Marine Laboratory. Additional support for this project was provided through Duke University, including Duke stipends for Summer Independent Study Students: R. Jones and K. Yang, part-time technical salary for C. Logan, partial support for CLVD, and contributions from the Marine Conservation Molecular Facility (T. Schultz and J. Carlsson) of the Duke University Marine Laboratory. We are very grateful for freely given assistance of taxonomic specialists around the world for taxa identifications. Molecular identification of certain taxa was carried out with the assistance of B. Vrijenhoek and S. Johnson at MBARI and was funded through the TAWNI program of the Chemosyntehtic Ecosystems Project (ChEss) of the Census of Marine Life.

\section{LITERATURE CITED}

Anderson MJ, Gorley RN, Clarke KR (2008) PERMANOVA+ for PRIMER: guide to software and statistical models. PRIMER-E, Plymouth

Andrews AH, Stone RP, Lundstrom CC, DeVogelaere AP (2009) Growth rate and age determination of bamboo corals from the northeastern Pacific Ocean using refined ${ }^{210} \mathrm{~Pb}$ dating. Mar Ecol Prog Ser 397:173-185

ANZECC/ARMCANZ (Australia and New Zealand Environment Conservation Commission/Agriculture and Resource Management Council of Australia and New Zealand) (2000) Australian and New Zealand guidleines for fresh and marine water quality. ANZECC and ARMCANZ, Canberra

Baker ET, German CR (2004) On the global distribution of hydrothermal vent fields. Geophys Monogr Ser 148: 245-266

Binns RA (2004) Eastern Manus Basin, Papua New Guinea: guides for volcanogenic massive sulphide exploration from a modern seafloor analogue. In: McConachy TF, McInnes BIA (eds) Copper-zinc massive sulphide deposits in Western Australia. Commonwealth Scientific and Industrial Research Organisation (CSIRO) Exploration \& Mining, North Ryde, p 59-80

> Both R, Crook K, Taylor B, Brogan S and others (1986) Hydrothermal chimneys and associated fauna in the Manus Back-Arc basin, Papua New Guinea. Eos Trans AGU 67:489-490

> Clarke KR (1993) Non-parametric multivariate analyses of changes in community structure. Aust J Ecol 18: $117-143$

Clarke KR, Gorley RN (2006) PRIMER v6: user manual/tutorial. PRIMER-E, Plymouth

Clarke KR, Warwick RM (2001) Change in marine communities: an approach to statistical analysis and interpretation, 2nd edn. PRIMER-E, Plymouth

Clarke KR, Chapman MG, Somerfield PJ, Needham HR (2006) Dispersion-based weighting of species counts in assemblage analyses. Mar Ecol Prog Ser 320:11-27 
CSIRO (Commonwealth Scientific and Industrial Research Organisation) (2005) Baseline environmental study, Eastern Manus Basin, Papua New Guinea. Proposal prepared by McConachy TF for CSIRO Exploration \& Mining, North Ryde

CSIRO (Commonwealth Scientific and Industrial Research Organisation) (2007) Baseline environmental study, Eastern Manus Basin, Papua New Guinea. Module 3. Report prepared by Johns SM, Yeats SJ, Hough RM, Binns RA, Rouse GW for CSIRO Exploration \& Mining, North Ryde

Desbruyères D, Hashimoto J, Fabri MC (2006) Composition and biogeography of hydrothermal vent communities in Western Pacific back-arc basins. In: Christie DM, Fisher CR, Lee SM, Givens S (eds) Back-arc spreading systems: geological, biological, chemical, and physical interactions. Geophys Monogr Ser 166:215-234

> Devey CW, Fisher CR, Scott S (2007) Responsible science at hydrothermal vents. Oceanography 20:162-171

Douglas JB (1980) Analysis with standard contagious distributions. Statistical Distributions in Scientific Work Series, Vol 4. International Co-operative Publishing House, Fairland, MD

> Dreyer JC, Knick KE, Flickinger WB, Van Dover CL (2005) Development of macrofaunal community structure in mussel beds on the northern East Pacific Rise. Mar Ecol Prog Ser 302:121-134

Elliott JM (1977) Some methods for the statistical analysis of samples of benthic invertebrates, 2nd edn. Freshw Biol Assoc Sci Publ 25:

Embley RW, Lupton JE, Massoth GJ, Urabe T and others (1998) Geological, chemical and biological evidence for recent volcanism at $17.5^{\circ} \mathrm{S}$ : East Pacific Rise. Earth Planet Sci Lett 163:131-147

Erickson KL (2007) Inactive sulfide mounds of the Manus Basin: invertebrate composition and potential for a chemoautotrophic food web. MS thesis, The College of William \& Mary, Williamsburg, VA

> Erickson KL, Macko SA, Van Dover CL (2009) Evidence for a chemautotrophically based food web at inactive hydrothermal vents (Manus Basin). Deep-Sea Res II 56: 1577-1585

Galkin SV (1997) Megafauna associated with hydrothermal vents in the Manus Back-Arc Basin (Bismarck Sea). Mar Geol 142:197-206

Gollner S, Riemer B, Martínez Arbizu O, Le Bris N, Bright M (2010) Diversity of meiofauna from the $9^{\circ} 50^{\prime} \mathrm{N}$ East Pacific Rise across a gradient of hydrothermal fluid emissions. PLoS ONE 5:e12321

Govenar B, Le Bris N, Gollner S, Glanville J, Aperghis AB, Hourdez S, Fisher CR (2005) Epifaunal community structure associated with Riftia pachyptila aggregations in chemically different hydrothermal vent habitats. Mar Ecol Prog Ser 305:67-77

Gray JS (1984) Ökologie mariner Sedimente: Eine Einführung. Springer-Verlag, Heidelberg

Green RH (1979) Sampling design and statistical methods for environmental biologists. John Wiley \& Sons, New York, NY

Gwyther D (2008) Environmental impact statement, Solwara 1 project, Vol A. Nautilus Minerals Niugini Limited. Coffey Natural Systems, Brisbane

Hashimoto J, Ohta S, Fiala-Médioni A, Auzende JM and others (1999) Hydrothermal vent communities in the Manus Basin, Papua New Guinea: results of the BIOACCESS cruises '96 and '98. InterRidge News 8:12-18
Hellberg ME (2009) Gene flow and isolation among populations of marine animals. Annu Rev Ecol Evol Syst 40: 291-310

Henry MS, Childress JJ, Figueroa D (2008) Metabolic rates and thermal tolerances of chemoautotrophic symbioses from Lau Basin hydrothermal vents and their implications for species distributions. Deep-Sea Res I 55: 679-695

Herzig PM, Petersen S, Hannington MD (1999) Epithermaltype gold mineralization at Conical seamount: a shallow submarine volcano south of Lihir Island, Papua New Guinea. In: Stanley CJ, Rankin AH, Bodnar RJ, Naden J and others (eds) Mineral deposits: processes to processing. Balkema, Rotterdam, p 527-530

> Hoagland P, Beaulieu S, Tivey MA, Eggert RG, German C, Glowka L, Lin J (2010) Deep-sea mining of seafloor massive sulfides. Mar Policy 34:728-732

Hrischeva E, Scott S (2008) Quality including trace elements of sediments from the South Su Knolls, Manus Basin, Bismarck Sea, Papua New Guinea. In: Nautilus Minerals Niugini Limited (ed) Environmental impact statement, Solwara 1 project, Vol B Appendices 4-7. Coffey Natural Systems, Brisbane

Humphris SE, Herzig PM, Miller DJ, Alt JC and others (1995) The internal structure of an active sea-floor massive sulphide deposit. Nature 377:713-716

Juniper SK (2004) Impact of the development of seafloor massive sulfides on deep-sea hydrothermal vent ecosystems. In: Office of Resource and Environmental Monitoring (ed) Minerals other than polymetallic nodules of the International Seabed Area. Proc Int Seabed Authority Workshop, Kingston Jamaica, June 26-30, 2000. International Seabed Authority, Kingston, p 273-302

Lampitt RS, Antia AN (1997) Particle flux in deep seas: regional characteristics and temporal variability. DeepSea Res I 44:1377-1403

> Lavelle JW, Mohn C (2010) Motion, commotion, and biophysical connections at deep ocean seamounts. Oceanography 23:90-103

Legendre P, Legendre L (1999) Numerical ecology, 2nd edn. Elsevier Science BV, Amsterdam

Levin LA, Mendoza GF, Konotchick T (2008) Macrofauna of active and inactive hydrothermal sediments from Solwara and South $\mathrm{Su}$, Manus Basin, Papua New Guinea. In: Nautilus Minerals Niugini Limited (ed) Environmental impact statement, Solwara 1 project, Vol B Appendices 4-7. Coffey Natural Systems, Brisbane, p 103-144

Levin LA, Mendoza GF, Konotchick T, Lee R (2009) Macrobenthos community structure and trophic releationships within active and inactive Pacific hydrothermal sediments. Deep-Sea Res II 56:1632-1648

> Luther GW, Rozan TF, Taillefert M, Nuzzio DB, Di Meo C, Shank TM, Lutz RA, Cary SC (2001) Chemical speciation drives hydrothermal vent ecology. Nature 410:813-816

> Machida Y, Hashimoto J (2002) Pyrolycus manusanus, a new genus and species of deep-sea eelpout from a hydrothermal vent field in the Manus Basin, Papua New Guinea (Zoarcidae, Lycodinae). Ichthyol Res 49:1-6

> Marcus J, Tunnicliffe V, Butterfield DA (2009) Post-eruption succession of macrofaunal communities at diffuse flow hydrothermal vents on Axial Volcano, Juan de Fuca Ridge, Northeast Pacific. Deep-Sea Res II 56:1586-1598 Podowski EL, Moore TS, Zelnio KA, Luther GW, Fisher CR (2009) Distribution of diffuse flow megafauna in two sites 
on the Eastern Lau Spreading Center, Tonga. Deep-Sea Res I 56:2041-2056

Rumohr H, Karakassis I, Jensen JN (2001) Estimating species richness, abundance and diversity with 70 macro benthic replicates in the Western Baltic Sea. Mar Ecol Prog Ser 214:103-110

Shannon CE, Weaver W (1949) The mathematical theory of communication. University of Illinois Press, Urbana, IL

Solomon M, Walshe JL (1979) The formation of massive sulfide deposits on the sea floor. Econ Geol 74:797-813

Soule SA, Fornari DJ, Perfit MR, Rubin KH (2007) New insights into mid-ocean ridge volcanic processes from the 2005-2006 eruption of the East Pacific Rise, $9^{\circ} 46^{\prime} \mathrm{N}-9^{\circ} 56^{\prime} \mathrm{N}$. Geology 35:1079-1082

Stewart-Oaten A, Murdoch WM, Parker KR (1986) Environmental impact assessment: 'pseudoreplication' in time? Ecology 67:929-940

Suzuki Y, Kojima S, Sasaki T, Suzuki M and others (2006a) Host-symbiont relationships in hydrothermal vent gastropods of the genus Alviniconcha from the Southwest Pacific. Appl Environ Microbiol 72:1388-1393

Suzuki Y, Kojima S, Watanabe H, Suzuki M and others (2006b) Single host and symbiont lineages of hydrothermal-vent gastropods Ifremeria nautilei (Provannidae): biogeography and evolution. Mar Ecol Prog Ser 315: $167-175$

Underwood AJ (1991) Beyond BACI: experimental designs for detecting human environmental impacts on temporal variations in natural populations. Aust J Mar Freshwater Res 42:569-587

Underwood AJ (1992) Beyond BACI: the detection of environmental impact on populations in the real, but variable, world. J Exp Mar Biol Ecol 161:145-178

Underwood AJ (1994) On beyond BACI: sampling designs that might reliably detect environmental disturbances. Ecol Appl 4:3-15

Underwood AJ (1997) Experiments in ecology: their logical

Editorial responsibility: Paul Snelgrove,

St. John's, Newfoundland and Labrador, Canada design and interpretation using analysis of variance. Cambridge University Press, Cambridge

Valesini FJ, Potter IC, Clarke KR (2004) To what extent are the fish compositions at nearshore sites along a heterogeneous coast related to habitat type? Estuar Coast Shelf Sci 60:737-754

Van Dover CL (2000) The ecology of deep-sea hydrothermal vents. Princeton University Press, Princeton, NJ

Van Dover CL (2003) Variation in community structure within hydrothermal vent mussel beds of the East Pacific Rise. Mar Ecol Prog Ser 253:55-66

Van Dover CL (2007) The biological environment of polymetallic sulphides deposits, the potential impact of exploration and mining on this environment, and data required to establish environmental baselines in exploration areas. In: Office of Resources and Environmental Monitoring (OREM) (ed) Polymetallic sulphides and cobalt-rich ferromanganese crusts deposits: establishment of environmental baselines and an associated monitoring programme during exploration. Proc Int Seabed Authority Workshop, Kingston Jamaica, 6-10 September 2004. International Seabed Authority, Kingston, p 169-190

Van Dover CL (2011) Mining seafloor massive sulfides and biodiversity: What is at risk? ICES J Mar Sci 68:341-348

Wang F, Zhou H, Meng J, Peng X and others (2009) GeoChip-based analysis of metabolic diversity of microbial communities at the Juan de Fuca Ridge hydrothermal vent. Proc Natl Acad Sci USA 106:4840-4845

> Warwick RM, Clarke KR (1996) Relationships between body-size, species abundance and diversity in marine benthic assemblages: facts or artefacts? J Exp Mar Biol Ecol 202:63-71

Wright M (2008) Oceanography at Solwara 1. In: Nautilus Minerals Niugini Limited (ed) Environmental impact statement, Solwara 1 project, Vol B Appendices 1-3. Coffey Natural Systems, Brisbane, p 269

Submitted: March 18, 2011; Accepted: February 3, 2012 Proofs received from author(s): April 12, 2012 